\title{
DESIGN OF THE NEW ARCH BRIDGE AT MIOVENI
}

Dima Alexandru, Ass.Prof, Technical University of Civil Engineering, Strength of Materials, Bridges and Tunnels Department, e-mail: sandudima@yahoo.com.

Răcănel Ionuţ Radu, Ass.Prof, Technical University of Civil Engineering, Strength of Materials, Bridges and Tunnels Department, e-mail: ionut@cfdp.utcb.ro.

\section{Abstract}

Road bridges with steel arches are used efficiently for medium and large spans. These solutions show advantages determined by the arches geometry, by the number and distributions of hangers and by the form and type of the arches bracing system.

The appearance of the welding as standard connection procedure for steel bridges, for road bridge decks two solutions are mainly used:

- the solution with a concrete slab acting together with the stringers and cross beams (the composite solution);

- the solution with orthotropic deck (the orthotropic deck consists in a network formed by the continuous longitudinal stiffeners and cross beams connected at the upper part by a steel plate).

In this paper a comparative study of the strength and fatigue checks performed on the new road bridge over river Argeşel near Mioveni in Argeş county is presented. The results are obtained using the Romanian standards STAS 1844-75 and SR 1911-1998 and the European norms SR EN 1990, SR EN 1993 and SR EN 1994. The deck was designed with two parallel steel arches, which are sustaining through vertical hangers a concrete slab connected with steel girders at the way level.

The aim of the paper is to outcome the safety factors obtained from checks performed on steel hangers using the Romanian standards with respect with those obtained using Eurocodes.

Keywords: arch bridge, steel deck, hanger, stiffening girder, grillage

\section{INTRODUCTION}

The unification of the design rules in Europe has determined important changes in the design, calculation and construction of the structures in general, but also of bridges particularly. In UE countries, the accepted standards at European level were completed with NAD's (National Application Documents) or National Annexes, those having as main target the validation, invalidation or 
changing of some design rules, principles or values used in the norms, by their adaption to the service and climate condition in each country.

In Romania, for steel and composite bridges, the use of Eurocodes lead to major changes of the design philosophy, imposed by the transition from a deterministic method (allowable resistance method) to a semi probabilistic method (limit state method). This change impose to carefully analyze the considered design parameters especially for the existing bridges which need to be strengthened.

Regarding the steel and composite bridges, some of the standards used in Romania until the introduction of Eurocodes are still valid in the present. This situation appears because some particular design situations are covered by national standards, but they are not covered by Eurocodes.

The aim of this paper is to show, by the aid of a simple case study on a new bridge, what are the differences, in terms of safety margins, between the results of the checks performed according national standards and Eurocodes respectively. Because of lack of space, very detailed checks for all structural elements of the bridge could not be done and for this reason only the results for resistance and fatigue checks of the steel hangers are compared. These types of of checks have be chosen because in Eurocodes doesn't exists explicit rules on these issues.

\section{DESCRIPTION OF THE ANALYZED BRIDGE}

The bridge over Argeşel river sustain the street I.C.Brătianu when entering in the town of Mioveni, in Arges county. The new bridge has replaced the old concrete bridge with three spans very strong damaged by the floods between 1999-2008. The new bridge superstructure consists of two separate parallel decks with steel arches. The carriage way with two traffic lanes in each direction is supported by a composite structure. The bridge substructure consists in two reinforced concrete abutments with deep foundations on piles having a diameter of $1.08 \mathrm{~m}$.

The composite structure of each deck is supported by two parallel steel arches using vertical circular steel hangers with a diameter of $\varnothing=100 \mathrm{~mm}$. At the ends of each hanger, the connection with the arches and the main girders forming the tie was designed with steel gussets and high strength bolts. The span of the decks is $48.00 \mathrm{~m}$, the distance in transverse direction between the axes of the arches is $\mathrm{B}=10.12 \mathrm{~m}$ and the arches rise is $12.00 \mathrm{~m}$. The geometry of the arches axes follow a circular arc having a radius $\mathrm{R}=30.00 \mathrm{~m}$. The deck at the way level consists in main girders - the ties, the cross beams and the stringers 
ROMANIAN JOURNAL

\section{OF TRANSPORT INFRASTRUCTURE}

which are connected to a concrete slab using steel studs. From these structural elements, the ties and the final cross beams have box cross section and the current cross beams and stringers have an open, double $\mathrm{T}$ cross section. The steel arches have also a box cross section. The steel hangers are verticals, placed each $6.00 \mathrm{~m}$ along the deck and for their connections with the arches and the ties high strength bolts M24, 10.9 were used. The upper wind bracing is formed with cross steel beams with variable height, having open double $\mathrm{T}$ welded cross section.

The lateral view and a cross section of the bridge are shown in figures 1 and 2.

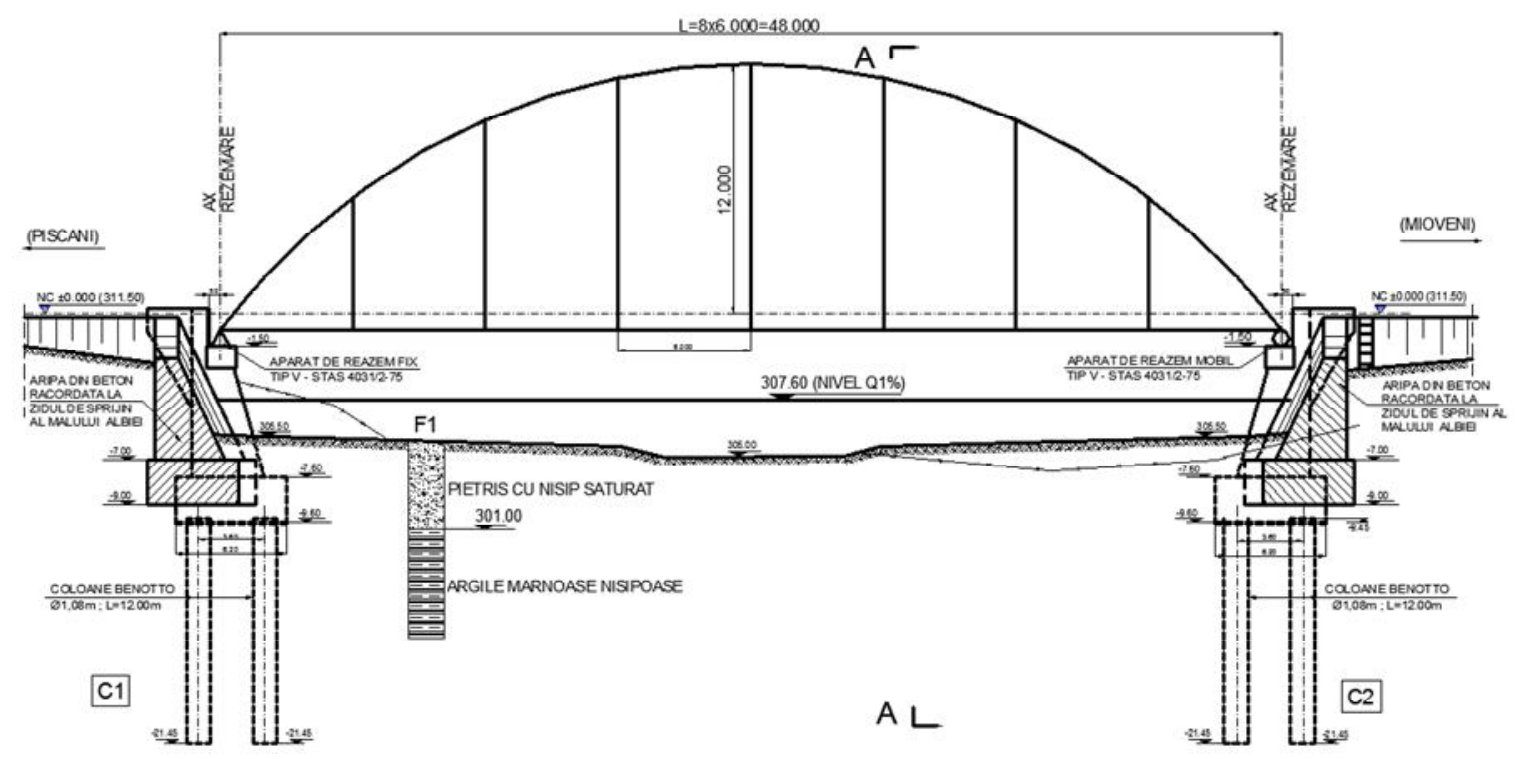

Figure 1. Lateral view of the bridge

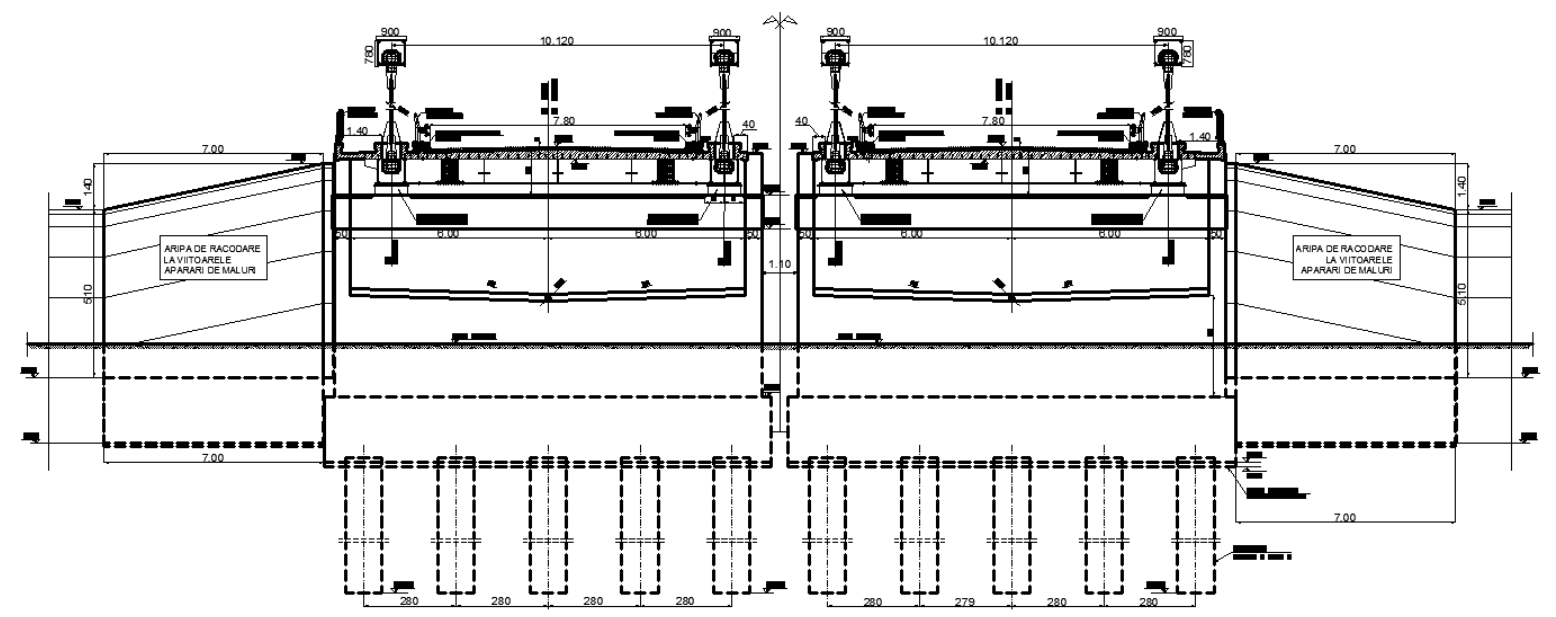

Figure 2. Cross section of the bridge 
ROMANIAN JOURNAL

OF TRANSPORT INFRASTRUCTURE

Dima Alexandru, Răcănel Ionuţ,

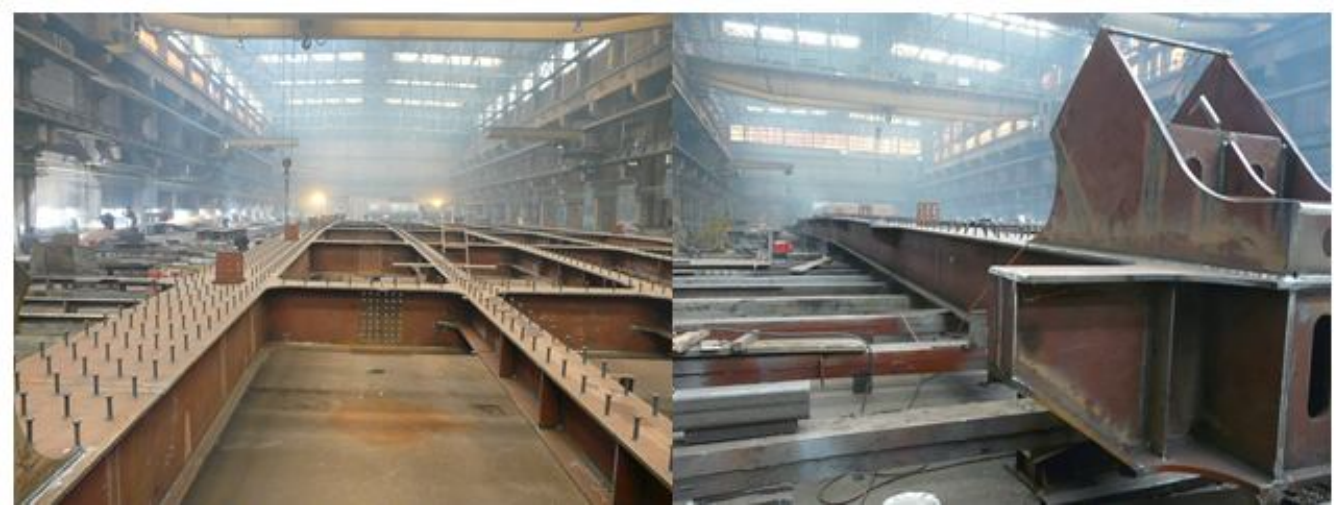

Figure 3. Aspects from the construction process in the factory

\section{NUMERICAL MODELS USED FOR THE ANALYSIS}

In order to perform the resistance and fatigue checks for the steel hangers, a finite elements model was built (Fig.4). Since the bridge substructure consists only in abutments placed each end of the bridge, those being structural elements with large stiffness, they were not included in the discrete model.
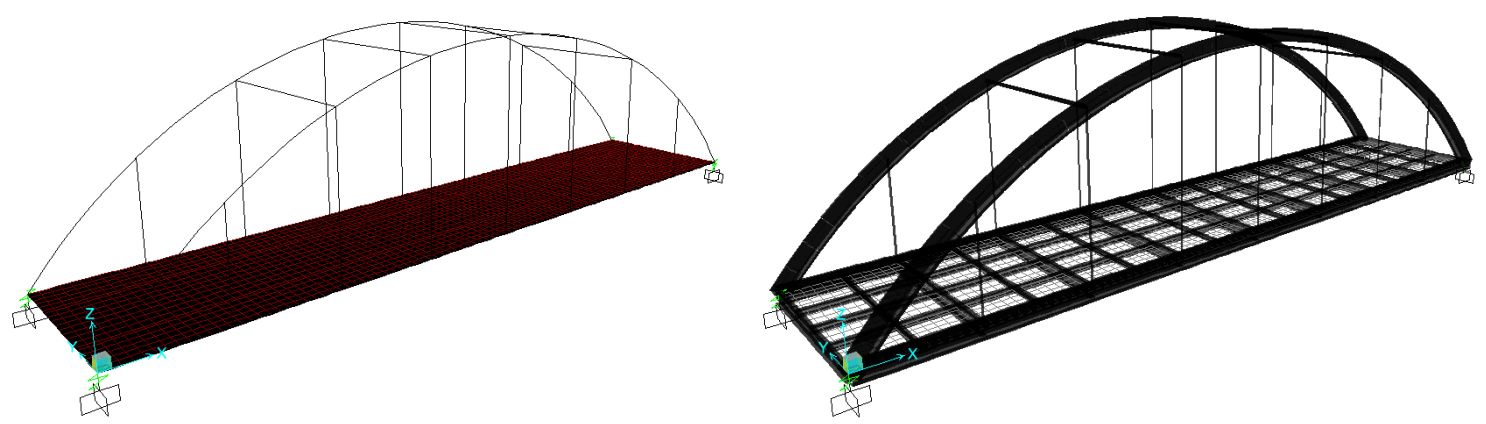

Figure 4. The used finite elements model

To model the deck at the way level, for the ties, cross beams and stringers two joints frame finite elements and for the concrete slab, four joints shell elements with plate and membrane behavior were used. The shell and frame elements are connected in the joints and the dimensions of the finite elements was established according to the distance between the shear connectors (studs). The steel hangers were modeled using also frame elements.

The position of finite elements axes for the structural elements forming the deck was established by considering the different level of the centroids of the cross sections. 
The behavior of the materials used into the model was considered as linear-elastic.

The actions taken into account were: the self-weight of the structure, the dead loads (way layers, footways, parapets), people crowd on the footways and moving loads using the convoys A30 and V80 for the checks according Romanian standards and loading models LM1 and FLM3 for the resistance and fatigue checks according Eurocodes. The nonlinear effects of creep and shrinkage were neglected.

\section{PERFORMED NUMERICAL ANALYSES AND CHECKS}

The internal forces on the cross section of structural elements were established using the finite element model presented above and running nonlinear staged construction analyses, considering the stages of applying loads on structure. The considered stages were:

Stage 1: the construction of steel structure (arches, deck at the way level, hangers);

Considered loads: self-weight of the structure, the weight of the formwork, the weight of the green concrete.

Stage 2: activating in the numerical model of the concrete slab after reaching the concrete class.

Considered loads: permanent loads (weight of the way layers, of the footways and guardrails).

Stage 3: using of the numerical model having all the elements activated.

Considered loads: actions due to the live load models and people crowds on the footways.

Through the performed nonlinear staged construction analysis, in each stage the stress and strains state in the previous stage was accounted for. In table 1 are summarized the values of the internal forces for the cross sections of considered structural elements. For the checks according to Eurocodes, the values of internal forces in table 1 are design internal forces $E_{d}$ (multiplied with the actions safety factors) and dynamic impact factors for live loads. The checks were performed on the most stressed four hangers. 
ROMANIAN JOURNAL

OF TRANSPORT INFRASTRUCTURE

Dima Alexandru, Răcănel Ionuț,

Design of the new arch bridge at Mioveni

Table 1. AXIAL FORCES IN HANGERS [kN]

\begin{tabular}{|c|c|c|c|c|}
\hline Hanger & $\mathrm{T} 1$ & $\mathrm{~T} 2$ & T3 & T4 \\
\hline Length $[\mathrm{m}]$ & 5.99 & 9.49 & 11.39 & 12 \\
\hline Cross section area $\left[\mathrm{m}^{2}\right]$ & $7.8 \times 10^{-3}$ & $7.8 \times 10^{-3}$ & $7.8 \times 10^{-3}$ & $7.8 \times 10^{-3}$ \\
\hline $\begin{array}{l}\text { Dynamic impact factor } \\
\psi_{\mathrm{ROM}, \mathrm{A} 30}\end{array}$ & 1.15 & 1.15 & 1.15 & 1.15 \\
\hline $\begin{array}{l}\text { Dynamic impact factor } \\
\psi_{\text {ROM,V80 }}\end{array}$ & 1 & 1 & 1 & 1 \\
\hline \multicolumn{5}{|c|}{ AXIAL FORCES ACCORDING TO STAS 10101/OB-77 AND STAS 3221} \\
\hline $\mathbf{N}_{\text {perman }}$ & 587 & 460 & 397 & 384 \\
\hline $\mathbf{N}_{\max , \mathbf{A} 30}$ & 204 & 153 & 131 & 126 \\
\hline $\mathbf{N}_{\min , \mathbf{A 3 0}}$ & 0 & 0 & 0 & 0 \\
\hline $\mathbf{N}_{\max , \text { V80 }}$ & 138 & 155 & 157 & 159 \\
\hline $\mathbf{N}_{\min , \mathrm{V} 80}$ & 0 & 0 & 0 & 0 \\
\hline $\mathbf{N}_{\max }$ with A30 & 821 & 635 & 547 & 528 \\
\hline $\mathbf{N}_{\min }$ with A30 & 587 & 460 & 397 & 384 \\
\hline \multicolumn{5}{|c|}{ AXIAL FORCES ACCORDING TO SR EN 1991-2 } \\
\hline $\mathbf{N}_{\mathbf{G}}$ & 795 & 622 & 534 & 517 \\
\hline $\mathbf{N}_{\text {max,LM1 }}$ & 219 & 215 & 208 & 207 \\
\hline $\mathbf{N}_{\min , \text { LM1 }}$ & 0 & 0 & 0 & 0 \\
\hline $\mathbf{N}_{\mathrm{Ed}, \max }$ & 1091 & 912 & 815 & 796 \\
\hline $\mathbf{N}_{\mathbf{E d}, \min }$ & 795 & 622 & 534 & 517 \\
\hline $\mathbf{N}_{\max , \text { FLM3 }}$ & 82.37 & 82.02 & 80.37 & 80.48 \\
\hline
\end{tabular}

\subsection{Checking of the hangers at ULS and fatigue}

Checking using the allowable stresses method was performed according to Romanian standards STAS 1844-75 and STAS 1911-75 and the check at ULS according to cu SR EN 1993-1-1.

The resistance check at ULS of the steel hangers according to SR EN 1993-1-1 was performed in a current section on their length. The structural detail considered for the fatigue check was the welded seam which ensure the connection of each hanger with the gussets placed on the arches and tie girder (Fig.5). 

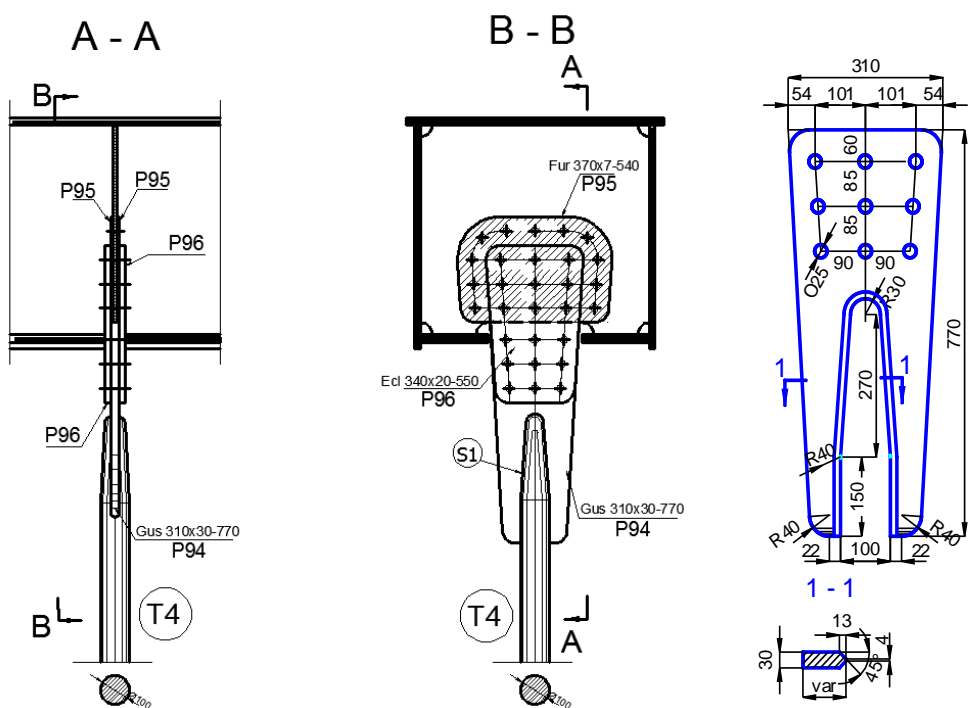

Figure 5. Hanger-steel arch connection detail, hanger T4

\subsubsection{Resistance and fatigue checks of hangers according to Romanian standards STAS 1844-75 and STAS 1911-75}

The resistance check of the hangers was performed according to STAS 1911-75 using the relationship:

$$
\sigma=\frac{N}{A} \leq \alpha \sigma_{a}
$$

where: $N$ is the axial force in the analyzed structural element;

$A$ is the gross cross section of the structural element;

$\alpha=1.00$ is a coefficient depending of internal force type (for axial force $\mathrm{N}, \alpha=1.00)$.

The fatigue check of the hangers was conducted according to STAS 184475 and STAS 1911-75:

$$
\sigma_{P}=\left(\sigma_{g}+\alpha \sigma_{p}\right) \leq \sigma_{R a}
$$

where: $\sigma_{P}$ is weighted theoretical stress calculated for a monoaxial stress state;

$\sigma_{g}$ is the stress produced by permanent actions;

$\sigma_{p}$ is the stress produced by traffic loads;

$\alpha=0.5$ (is a weight coefficient depending on the bridge loading class: for loading class $\mathrm{E}, \alpha=0.5$ );

$\sigma_{R a}$ is the fatigue allowable stress depending on steel grade, asymmetry ratio of fatigue cycles and the category of the structural detail. 
For the considered study case $\sigma_{R a}$ was calculated for $R_{\sigma}$ values corresponding to each hanger for structural detail C, detail 9, table 17 in STAS 1911-75, for the steel grade OL52.

\subsubsection{Steel hangers resistance and fatigue checks according to Eurocodes}

The ultimate limit state check of steel hangers has to be performed according SR EN 1993-1-1 as follows:

$$
\frac{N_{E d}}{N_{t, R d}} \leq 1
$$

where: $N_{E d}$ design tensile axial force;

$N_{t, R d}$ design tensile resistance established using the relationship:

$$
N_{t, R d}=\frac{A f_{y}}{\gamma_{M 0}}
$$

where:

$A$ is the gross cross section of the element;;

$f_{v}$ yield strength of the steel;

$\gamma_{M 0}=1$ is a safety factor for the material.

The fatigue check of the hangers has to be made according to SR EN 1993-1-9 and SR EN 1993-2 using the criterion:

$$
\gamma_{F f} \cdot \Delta \sigma_{E 2} \leq \frac{\Delta \sigma_{c}}{\gamma_{M f}}
$$

where: $\gamma_{F f}=1$ (partial safety factor for fatigue actions effect);

$\gamma_{M f}=1.35$ (partial safety factor of fatigue strength);

$\Delta \sigma_{c}$ is the reference value for fatigue resistance which for the structural detail used in the case of hangers is $105 \mathrm{~N} / \mathrm{mm}^{2}$, according to SR EN 1993-1-11.

$$
\Delta \sigma_{E 2}=\lambda \Delta \sigma_{p}
$$

(dynamic impact factor included in the values of internal forces from FLM3) where: $\lambda$ is the damage equivalent factor for road bridges;

$\Delta \sigma_{p}$ the stress range due to the load model FLM3;

$$
\Delta \sigma_{p}=\sigma_{p, \text { max }}-\sigma_{p, \text { min }}
$$

where: $\sigma_{p, \max }, \sigma_{p, \min }$ are maximum and minimum stresses from the action of the load model FLM3. 
ROMANIAN JOURNAL

\section{OF TRANSPORT INFRASTRUCTURE}

The values of the impact factors for the ultimate limit state checks according EUROCODE were established on the basis of axial force in the hangers critical influence line length. Although the axial force influence line surfaces don't change sign along the span, in order to be placed on the safe side, the critical influence line length was considered as the distance between two inflexion points (Fig.6). In the figure, the axial force influence surface for hanger T4 is shown. The results of the resistance checks are summarized in table 2 and of fatigue checks in table 3.

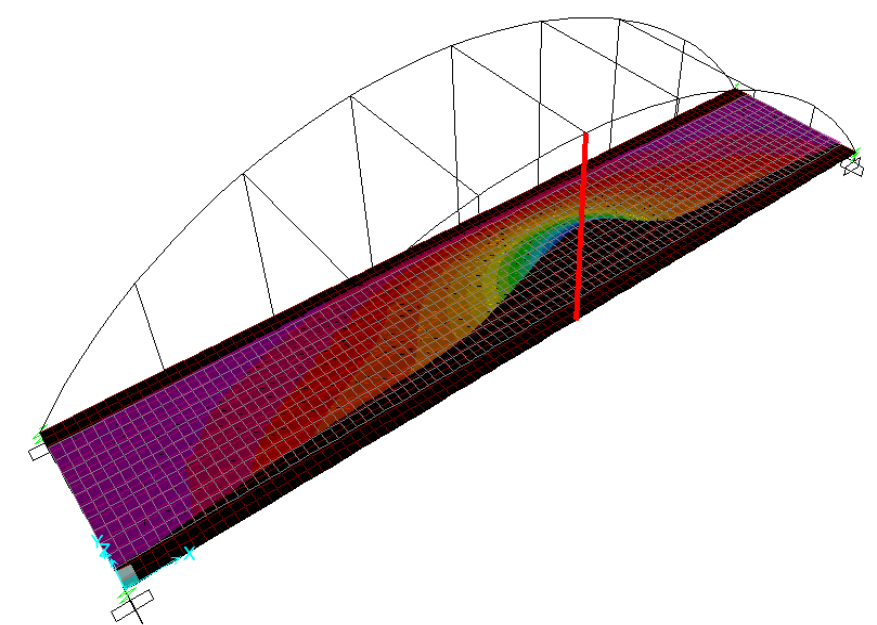

Figure 6. Axial force influence surface for hanger T4

Table 2. Results for resistance checks

\begin{tabular}{|l|c|c|c|c|}
\hline Hanger & T1 & T2 & T3 & T4 \\
\hline \multicolumn{4}{|c|}{ Resistance checks according to SR $1911-75$} \\
\hline$\sigma_{\text {max }}\left[\mathbf{N} / \mathbf{m m}^{2}\right]$ & 103 & 80 & 69 & 67 \\
\hline$\alpha \sigma_{a}=\mathbf{1 . 0 x} \sigma_{a}\left[\mathbf{N} / \mathbf{m m}^{2}\right]$ & 231 & 231 & 231 & 231 \\
\hline$\sigma_{\text {max }} / \alpha \sigma_{a}$ & 0.45 & 0.35 & 0.30 & 0.29 \\
\hline Safety margin & 2.22 & 2.86 & 3.33 & 3.45 \\
\hline \multicolumn{4}{|c|}{ ULS checks according to SR EN $1993-1-1$} \\
\hline $\mathbf{N}_{\mathbf{E d}}[\mathbf{k N}]$ & 1091 & 912 & 815 & 796 \\
\hline $\mathbf{N}_{\mathbf{t}, \mathbf{R d}}[\mathbf{k N}]$ & 2592 & 2592 & 2592 & 2592 \\
\hline $\mathbf{N}_{\mathbf{E d}} / \mathbf{N}_{\mathbf{t}, \mathbf{R d}}$ & 0.42 & 0.35 & 0.31 & 0.31 \\
\hline Safety margin & 2.38 & 2.86 & 3.23 & 3.23 \\
\hline
\end{tabular}


ROMANIAN JOURNAL

OF TRANSPORT INFRASTRUCTURE

Table 3. Results for fatigue checks

\begin{tabular}{|l|c|c|c|c|}
\hline Hanger & $\mathrm{T} 1$ & $\mathrm{~T} 2$ & $\mathrm{~T} 3$ & $\mathrm{~T} 4$ \\
\hline \multicolumn{4}{|c|}{ Fatigue checks according } & \multicolumn{1}{l|}{ STAS $1911-75$} \\
\hline$R_{\sigma}=\sigma_{P \min } / \sigma_{P \max }$ & 0.85 & 0.86 & 0.86 & 0.86 \\
\hline$\sigma_{R a}\left[\mathbf{N} / \mathbf{m m}^{2}\right]$ & 160 & 160 & 160 & 160 \\
\hline$\sigma_{P}\left[\mathbf{N} / \mathbf{m m}^{2}\right]$ & 87.73 & 68.30 & 58.88 & 56.91 \\
\hline$\sigma_{P} / \sigma_{R a}$ & 0.55 & 0.43 & 0.37 & 0.36 \\
\hline Safety margin & 1.82 & 2.33 & 2.70 & 2.78 \\
\hline \multicolumn{4}{|c|}{ Fatigue checks according to SR EN $1993-2$ and SR EN $1993-1-9$} \\
\hline$\lambda$ moderate traffic $^{2}$ & 1.57 & 1.57 & 1.57 & 1.57 \\
\hline$\Delta \sigma_{E 2}\left[\mathbf{N} / \mathbf{m m}^{2}\right]$ moderate traffic & 22.05 & 21.95 & 21.51 & 21.54 \\
\hline$\lambda$ heavy traffic $^{2}$ & 2.07 & 2.07 & 2.07 & 2.07 \\
\hline$\Delta \sigma_{E 2}\left[\mathbf{N} / \mathbf{m m}^{2}\right]$ heavy traffic & 29.09 & 28.97 & 28.38 & 28.42 \\
\hline$\gamma_{F f} \cdot \Delta \sigma_{E 2} \cdot \gamma_{M f} / \Delta \sigma_{c}$ moderate traffic & 0.283 & 0.282 & 0.277 & 0.277 \\
\hline$\gamma_{F f} \cdot \Delta \sigma_{E 2} \cdot \gamma_{M f} / \Delta \sigma_{c}$ heavy traffic & 0.374 & 0.372 & 0.365 & 0.365 \\
\hline Safety margin moderate traffic & 3.53 & 3.55 & 3.61 & 3.61 \\
\hline Safety margin heavy traffic & 2.67 & 2.69 & 2.74 & 2.74 \\
\hline
\end{tabular}

In figures 7 and 8 are presented the graphs containing the values of safety margins obtained following the checks performed according to SR EN 1993-1-9 and SR EN 1993-2 where the symbols are: TM (moderate traffic) and TG (heavy traffic).

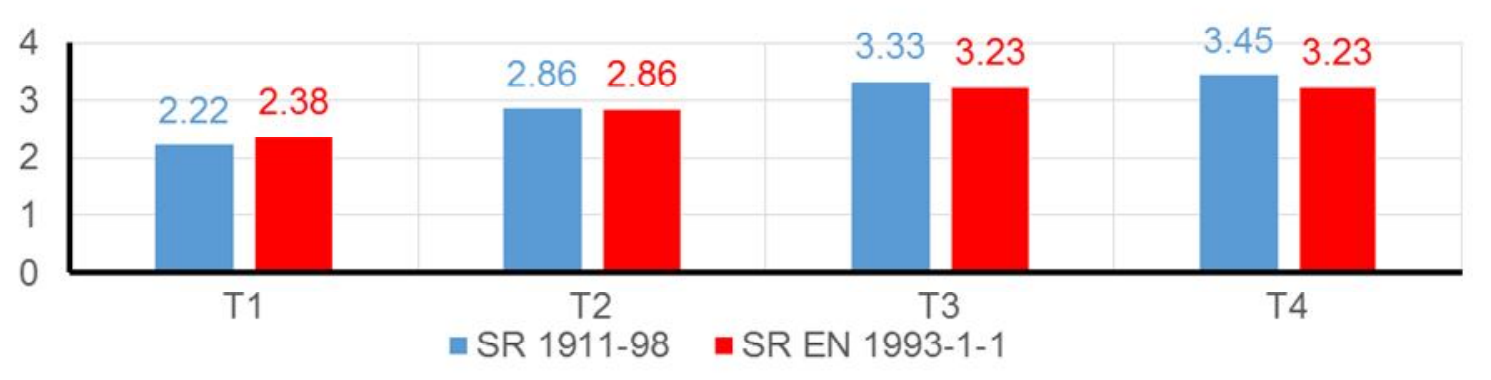

Figure 7. Safety margins for resistance checks 
ROMANIAN JOURNAL

OF TRANSPORT INFRASTRUCTURE

Dima Alexandru, Răcănel Ionuț,

Design of the new arch bridge at Mioveni

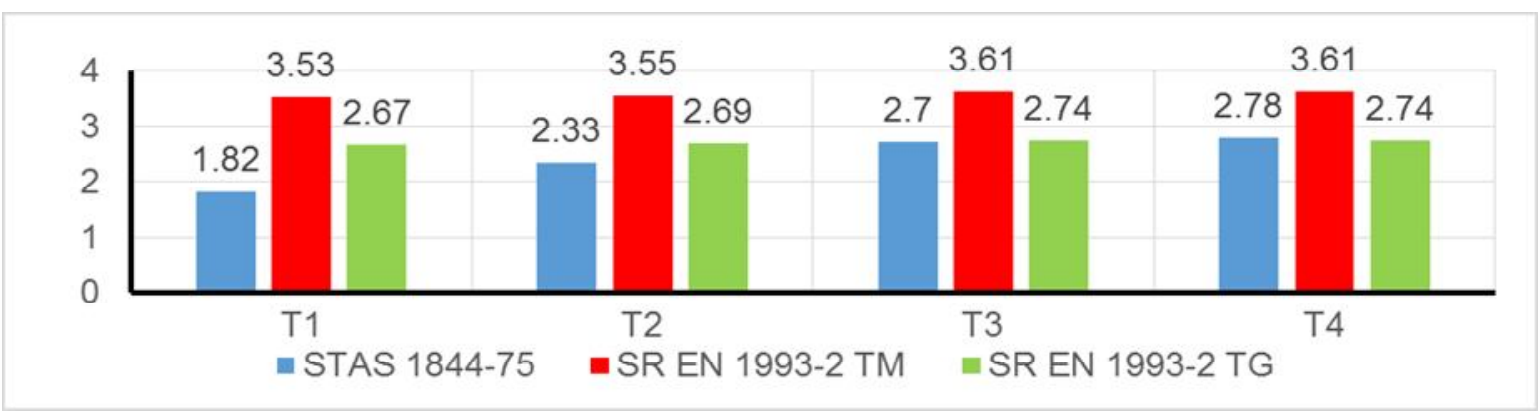

Figure 8. Safety margins for fatigue checks

\section{CONCLUSIONS}

In this paper the results of a comparative study regarding the resistance and fatigue checks for the hangers of a road arch bridge with composite deck are presented. The checks were performed according to Romanian standards STAS 1844-75 and STAS 1911-75 and to European standards SR EN 1993-1-1, SR EN 1993-1-9 and SR EN 1993-2 respectively.

The results presented in the tables and graphs above show that both, for resistance and fatigue checks, the criteria are fulfilled no matter the used standard.

Regarding the safety margins values which are with respect to the limit values of resistances, it can be concluded that for the resistance checks the results are very close for both used standards - Romanian standards and Eurocodes, but for the fatigue checks the results according to Eurocodes are close to those obtained with the Romanian standards only for heavy traffic, this aspect showing the correctness of Romanian norms.

\section{REFERENCES}

[1] ***:"STAS 1844-75 Steel bridges for roads. Design requirements", IRS, Bucharest, Romania, 1975

[2] ***: "STAS 1911-75 Steel bridges for railways. Design requirements", IRS, Bucharest, Romania, 1998

[3] U.K. GHOSH: "Design and construction of steel bridges", Taylor\&Francis Group, London, U.K., 2006

[4]. ***: "Guide méthodologique Eurocode 3 et4 Application aux ponts-routes mixtes acier-béton", SÉTRA, Bagneux Cedex, France, 2007.

[5] ***: "SR EN 1993-2 Design of composite steel and concrete structures. Part 2: general rules and rules for bridges", ASRO, Bucharest, Romania, 2007

[6] G. PARKE, N. HEWSON: "ICE Manual of bridge engineering - Second Edition", Thomas Telford Ltd., London, U.K., 2008 